\title{
EDITORIAL
}

\section{Platelet-rich plasma in skin rejuvenation}

\section{Shahin Aghaei}

Iran University of Medical Sciences, Tehran, Islamic Republic of Iran

$\mathrm{P}$ latelet-rich plasma (PRP) is a concentrate of platelets that has broadly been used to speed up the restoration of human skin tissues. Procedures of its preparation would differ from method to method, depending on the concentration of various participating ingredients, including proteins ${ }^{[1]}$. Positive reports are mostly based on case studies rather than large randomized and placebo-controlled trials ${ }^{[2,3]}$.

In the field of skin rejuvenation, the theory is that PRP, through various secreted growth factors and cytokines, may promote collagen production and fibroblast multiplying in aged skin. PRP has a high concentration of growth factors such as platelet-derived growth factor (PDGF), transforming form growth factor (TGF), those secreting from endothelial vessels i.e. vascular endothelial growth factor (VEGF), and lastly, those factors with serum insulin-like activity, i.e. insulin-like growth factor (IGF), as well as plasma proteins such as fibrin, fibronectin, and vitronectin. PRP increases the presence of proteins that regulate G1 cell cycle, collagen type I, matrix-derived metalloproteinase-1 (MMP-1) and MMP-2 within human skin fibroblasts (HSF), and messenger ribonucleic acid (mRNA) in human dermal fibroblasts $^{[4,5]}$.

A few years ago, in some initial clinical studies with platelet concentrates in the patients attending plastic and orthopedic surgery departments, some benefits have been shown. Conversely, interests have also declined due to some significant problems such as cost, the amount of blood required, the need for special tools and experienced personnel, and most importantly the lack of clinically significant advantage. Hence, a new simple formulation containing autologous platelet-derived material called Selphyl (Aesthetic Factors, Bethlehem, PA, USA) permits rapid and low-priced generation of a matrix of fibrin derived from platelet matrix, which could be used to improve healing after skin procedures, as well as to rectify he deep nasolabial folds ${ }^{[6,7]}$.

The combination of PRP and hyaluronic acid injections improved facial skin with noticeable and statistically substantial enhancement. The improvements are more noteworthy with higher number of injections ${ }^{[8]}$. A three-month study of 24 patients undergoing face and neck rejuvenation via monthly PRP injections revealed reasonable results through subjective and objective measures $^{[9]}$.

In a study with 20 volunteers who received one single intradermal PRP injection, results showed that it was well tolerated and proficient in revitalizing facial skin, thus making a noteworthy improvement of wrinkles, mainly at the nasolabial folds ${ }^{[10]}$. Another study showed that combining PRP therapy with fractional resurfacing resulted in a rise in dermal elasticity and collagen thickness as well as a decrease in erythema ${ }^{[11]}$. Combining PRP with fractional lasers or subcision suction to treat atrophic acne scars has been shown to shorten the healing time, as well as to diminish erythema and edema, while encouraging keratinocyte, fibroblast, and collagen proliferation $^{[12-14]}$.

There might be some side effects when using PRP that the patient must be aware of before the procedure. The most common side effects include pain in the injured area, infection, no improvement in the injured area, allergic reaction, blood clot, skin discoloration, and even blindness, although rarely so ${ }^{[15-17]}$.

PRP is considered a novel therapy with some studies indicating its effectiveness in esthetic dermatology. Combining of PRP with some other modality treatments is mostly exciting. Forthcoming studies should contain control groups, as well as association of split-body evaluations, to lessen inter-subject inconsistency and to establish the safety and efficacy of PRP for clinical applications.

\section{References}

1. Cervelli V, Palla L, Pascali M, De Angelis B, Curcio BC, et al. Autologous platelet-rich plasma mixed with purified fat graft in aesthetic plastic surgery. Aesth Plast Surg 2009; 33(5): 716-721. doi: 10.1007/s00266-009-9386-0.

2. Rivers KJ. Plasma-rich plasma: Should we wait for the verdicts? J Cut Med and Surg 2014; 18(3): 147-148.

3. Arshdeep, Kumaran MS. Platelet-rich plasma in dermatology: Boon or a bane? Indian J Dermatol Venereol Leprol 2014; 80(1): 5-14. doi: 10.4103/0378-6323.125467.

4. Cho JW, Kim SA, Lee KS. Platelet-rich plasma induces

Copyright (C) 2017 Aghaei S. This is an Open Access article distributed under the terms of the Creative Commons Attribution-NonCommercial 4.0 International License (http://creativecommons.org/licenses/by-nc/4.0/), permitting all non-commercial use, distribution, and reproduction in any medium, provided the original work is properly cited. 
increased expression of G1 cell cycle regulators, type I collagen, and matrix metalloproteinase- 1 in human skin fibroblasts. Int J Mol Med 2012; 29(1): 32-36. doi: 10.3892/ijmm.2011.803.

5. Kim DH, Je YJ, Kim CD, Lee YH, Seo YJ, et al. Can platelet-rich plasma be used for skin rejuvenation? Evaluation of effects of platelet-rich plasma on human dermal fibroblast. Ann Dermatol 2011; 23(4): 424-431. doi: 10.50 21/ad.2011.23.4.424.

6. Sclafani AP. Applications of platelet-rich fibrin matrix in facial plastic surgery. Facial Plast Surg 2009; 25(4): 270-276. doi: 10.1055/s-0029-1242033.

7. Sclafani AP. Platelet-rich fibrin matrix for improvement of deep nasolabial folds. J Cosmet Dermatol 2010; 9(1): 66-71. doi: 10.1111/j.1473-2165.2010.00486.x.

8. Ulusal BG. Platelet-rich plasma and hyaluronic acid-An efficient biostimulation method for face rejuvenation. J Cosmet Dermatol 2017; 16(1): 112-119. doi: 10.1111 /jocd.12271.

9. Redaelli A, Romano D, Marcianò A. Face and neck revitalization with platelet-rich plasma (PRP): Clinical outcome in a series of 23 consecutively treated patients. J Drugs Dermatol 2010; 9(5): 466-472.

10. Elnehrawy NY, Ibrahim ZA, Eltoukhy AM, Nagy HM. Assessment of the efficacy and safety of single platelet-rich plasma injection on different types and grades of facial wrinkles. J Cosmet Dermatol 2017; 16(1): 103-111. doi: 10.1111/jocd.12258.

11. Min-Kyung S, Jong-Ho L, Sang-Jun L, Nack-In K. Platelet-rich plasma combined with fractional laser therapy for skin rejuvenation. Dermatol Surg 2012; 38(4): 623-630 doi: 10.1111/j.1524-4725.2011.02280.x.

12. Lee JW, Kim BJ, Kim MN, Mun SK. The efficacy of autologous platelet rich plasma combined with ablative carbon dioxide fractional resurfacing for acne scars: A simultaneous split-face trial. Dermatol Surg 2011; 37(7): 931-938. doi: 10.1111/j.1524-4725.2011.01999.x.

13. Gawdat HI, Hegazy RA, Fawzy MM, Fathy M. Autologous platelet rich plasma: Topical versus intradermal after fractional ablative carbon dioxide laser treatment of atrophic acne scars. Dermatol Surg 2014; 40(2): 152-161. doi: 10.1111/dsu.12392.

14. Abou Khedr NAE, Hussein TM, Abd El-Fatah AME. Comparing the role of subcision suction method with and without the injection of platelet-rich plasma in the treatment of depressed scars. J Surg Dermatol 2017; 2(2): 88-97; doi: 10.18282/jsd.v2.i2.90.

15. Abuaf OK, Yildiz H, Baloglu H, Bilgili MR, Simsek HA, Dogan B. Histologic evidence of new collagen formulation using platelet rich plasma in skin rejuvenation: A prospective controlled clinical study. Ann Dermatol 2016; 28(6): 718-724. doi: 10.5021/ad.2016.28.6.718.

16. Uysal CA, Ertas NM. Does platelet-rich plasma therapy increase pigmentation? J Craniofac Surg 2016. In Press.

17. Kalyam K, Kavoussi SC, Ehrlich M, Teng CC, Chandha N, et al. Irreversible blindness following periocular autologous platelet-rich plasma skin rejuvenation treatment. Ophthal Plast Reconstr Surg 2016. In Press.

Keywords: Platelet-rich plasma; skin rejuvenation; side effects

Citation: Aghaei S. Platelet-rich plasma in skin rejuvenation. J Surg Dermatol 2017; 2(2): 61-62; http://dx.doi.org/10.18 282/jsd.v2.i2.150.

Received: $6^{\text {th }}$ April 2017; Published Online: $18^{\text {th }}$ April 2017

Correspondence to: Shahin Aghaei, Roonik Skin Clinic, \#78, Asad-abadi Ave., Tehran, Islamic Republic of Iran, shahinaghaei@yahoo.com. 